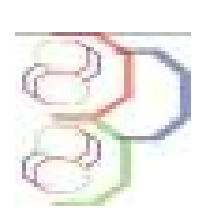

Journal of Applied Biosciences 111: 10925-10933

ISSN 1997-5902

\title{
Optimization of production of Microbial Exopolysaccharides (EPS) with essential oils from two medicinal plants
}

\author{
Benhadria Mekhici K1․, Tir Touil Meddah A1 ., Meddah Boumédiene ${ }^{1}$ \\ Bioconversion, Microbiological, Engineering and Health Security Laboratory. University of Mustapha Stambouli \\ Mascara, 29000. Mascara Algeria. \\ E-mail: Benhadria_k@yahoo.fr
}

Original submitted in on 21st December 2016. Published online at www.m.elewa.orgon 31st March 2017 http://dx.doi.org/104314/jab.v111i1.9

\begin{abstract}
Objective: The aim of our study is to evaluate the effect of essential oils of two medicinal plants: Atriplex halimus and Haloxylon scoparium on the production of EPS by four probiotic strains.

Methodology and results: Exopolysaccharides (EPSs) of lactic acid bacteria have potential for development and exploitation as food additives and functional food ingredients with both health and economic benefits. In this study, EPS production was carried at sucrose broth with different parameters (inoculum size, temperature, $\mathrm{pH}$, incubation period, sucrose concentration, oxygen tension). In addition, under an optimized condition the effect of essential oils of two medicinal plants: Atriplex halimus (A.H.) and Haloxylon scoparium (H.S.) was evaluated on EPS production by four strains (Leuconostoc sp., Lactobacillus sp. and two strains Pediococcus sp.). The production kinetics and exopolysaccharide yields were strongly dependent on the fermentation conditions. Physical factors such as temperature, $\mathrm{pH}$ and oxygen tension had a primordial importance. Conditions leading to higher levels of EPS production depends on strains and adequate concentrations of sucrose $(50 \mathrm{~g} / \mathrm{l}), \mathrm{pH}(6,5$ for Leuconostoc sp. and Pediococcus sp., 2; 4,5 for Lactobacillus sp. and 5 for Pediococcus sp. 1, incubation period (18 hours), temperature $\left(37^{\circ} \mathrm{C}\right.$ from Leuconostoc sp. and Pediococcus sp. $1,30^{\circ} \mathrm{C}$ from Lactobacillus sp., $50^{\circ} \mathrm{C}$ from Pediococcus sp. 2) and medium of production (broth sucrose). The introduction of essential oils $(150 \mu \mathrm{l})$ of tested plants improved the production of EPS from $7.9-9.73 \mathrm{mg} / \mathrm{ml}$ of all strains to $15.2-16.28$ with essential oils of Atriplex halimus and $11.6-13.2 \mathrm{mg} / \mathrm{ml}$ with essential oil of Haloxylon scoparium. Results showed an important stimulation of the exopolysaccharides production by essential oils of two plants (A.H. and H.S.)

Conclusion and Application of results: Our strains have shown their ability to produce maximum levels of EPS in the case of the addition of essential oils extracted from medicinal plants. These substances can be used as additives in the food industry to increase the productivity of the lactic strains of EPS as well as in the pharmaceutical field to prepare some medications.
\end{abstract}

Key words: exopolysaccharides, optimization, essential oils, medicinal plants, Lactic Acid Bacteria. 


\section{INTRODUCTION}

Polysaccharides are the most diverse families of biopolymers. Many kinds of polysaccharides are found to have wide applications likes thickeners, stabilizers, emulsifiers, gelling agents and water binding agents in food industry, plasma substitutes, for skins or for transport of active ingredients in the medical field. Much attention has been focused on polysaccharides for their multiple bioactivities and pharmacological actions (Xiaohua and Lina, 2009). The primary structure of polysaccharides varies in composition and sequence, and different kinds of polysaccharides are characterized by regular repeating units. The bioactivity of a given polysaccharide is closely related to its structure and physicochemical properties (Xiaohua and Lina, 2009). Microbial exopolysaccharides are extracellular polysaccharides (EPS) produced by many microorganisms (Kumar et al., 2007), mainly involved in cell adhesion and protection, and often covalently bound to the cell surface in the form of capsules, or secreted into the extracellular environment in the form of slime (Sivakumar et al., 2012). Lactic acid bacteria (LAB) produced EPS have been widely studied for their physicochemical properties and potential health effects during the last decades (Degeest et al., 2002) in view their application in food industry as thickeners, stabilizers, emulsifiers, binders, gelling agents as well as the beneficial physiological effects on human health, such as antitumour activity, immunomodulating bioactivity and antimutagenicity (Van Calsteren et al.,

\section{MATERIALS AND METHODS}

Lactic acid strains and culture medium: The lactic acid bacterial Leuconostoc sp. (S1), Lactobacillus sp. (S2), and 2 strains Pediococcus sp (S3 and S4) were isolated from cow milk, Faecal sample of infant (1 month) and fish respectively. All strains were cultured on anaerobiosis at $37^{\circ} \mathrm{C}$ for 48 hours in Man Rogosa Sharp agar (de Man et al. 1960), and purified with cultures on MRS broth. The initial bacterial load ranged from 7 to $8 \mathrm{Log} \mathrm{CFU} / \mathrm{mL}$.

Medicinal plants: Two plants have been used: Atriplex halimus L. (A.H.) and Haloxylon scoparium Pomel (H.S.) collected from south west of Algeria, Mechria and Naâma respectively. The plants have dried away from light and moisture.
2002; Doleyres et al., 2005). The EPS are high molecular weight polymers, which are long chain composed of sugar residues and secreted by microorganisms into the surrounding environment. These molecules consist of a complex mixture of macro molecular polyelectrolytes including polysaccharides, proteins and nucleic acids. Each comprises of variable molecular mass and structural properties (Vijayabaskar et al., 2011). The majority of EPSs are heteropolysaccharides (HePSs) containing long chain repeating subunits of two or more monosaccharides and they can be generated in large quantities by microrganisms, such as dextran by Leuconostoc mesenteroides, Streptococcus mutan, Gluconobacter oxydan; Levan by Lactobacillus reuteri strain 121; and fructan by Lactobacillus sanfranciscensis LTH2590 (Van GeelSchutten et al., 1998; De Vuyst and Degeest, 1999; van Hijum et al., 2001; Korakli et al., 2002; Naessens et al., 2005). The low production yield of these molecules represents a disadvantage for their uses in food industry, which makes development of new strategies for improved synthesis of EPS. In the present study, an attempt was made to optimize the production of exopolysaccharides by lactic acid bacteria. Process optimization was performed to maximize the production of EPS by addition of essential oils of two medicinal plants: Atriplex halimus (GUETTAF) and Haloxylon scoparium (REMTH).

Extraction of essential oils: This operation was carried out in three main steps; hydrodistillation which is to bring to boil the mixture water and the dry plant: Atriplex halimus and Haloxylon scoparium. Then, from the distillate recovered from the previous step, organic phase were the essential oil must be removed from the aqueous phase with a solvent (cyclohexane). Finally, the organic material is placed in a rotary evaporator to recover the pure essential oil (Willem, 2004). Essential oils extracted were sterilized by filtration $(0.45 \mu \mathrm{m})$.

Optimization of production of exopolysaccharides : Medium condition and other bacteria growth conditions are important factors for EPS production (Xu et al., 2003; 2010; Kaditzky and Vogel, 2008; Hao et al., 2010). This 
step is to vary successively each of the factors keeping the other constant. Media (10 ml) were inoculated (1\%) with strains pregrown in MRS broth (culture of 18 hours). The optical density $(O D=600 \mathrm{~nm})$ is equal to a bacterial load of $2 \times 10^{8} \mathrm{CFU} / \mathrm{mL}$

a. Medium of production: In order to evaluate the effect of medium on EPS production, the following media was tested: MRS and sucrose broth. Sucrose broth was prepared with sucrose $50 \mathrm{~g} / \mathrm{l}$, tryptone $10 \mathrm{~g} / \mathrm{l}$, Beef extract $5 \mathrm{~g} / \mathrm{l}$ and $\mathrm{KH}_{2} \mathrm{PO}_{4} \mathrm{~g} / \mathrm{l}, \mathrm{pH}$ of medium was adjusted to 6,5 .

b. Concentration of inoculum: The initial concentration of inoculum was varied as follows $\left(10^{6}\right.$, $\left.10^{7}, 10^{8}\right)$, then incubation was carried out at $37^{\circ} \mathrm{C}$ for 24 hours.

c. Temperature: In order to determine the suitable temperature improved production of EPS, strains were grown at different temperatures: $30^{\circ}, 37^{\circ}, 45^{\circ}$ and $50^{\circ}$ $C$ for 24 hours.

d. $\quad \mathrm{pH}$ : To set the $\mathrm{pH}$ leading to optimal production of EPS, four different (3; 4.5; 5 and 6.5$)$ were used. Cultures have incubated during 24 hours.

e. Incubation period: EPS production was investigated after incubation during 18, 24 and 48 hours.

$\mathrm{f}$. Conditions of aeroanaerobiosis: The strains were cultivated in aerobiosis means growth in the presence of oxygen and anaerobiosis, which consists of life in the absence of oxygen under optimal conditions of the concentration of inoculum, $\mathrm{pH}$, and temperature and incubation period.

g. Substrate: In the present experiment, strains were cultivated with different concentrations of sucrose: $30,50,70$ and $90 \mathrm{~g} / \mathrm{l}$.

\section{RESULTS AND DISCUSSION}

Yield of extraction of E.O: Yields of extraction were 0.028 what should be the result of Chikhi I., 2013 for Atriplex halimus and $0.019 \%$ for Haloxylon scoparium. Otmani F., 2014 have found a performance of extraction of essential oil of Haloxylon scoparium harvested from Naâma of $0.019 \%$.

Optimization of production of EPS: The results from initial assays indicated that the ideal conditions for the synthesis of EPS by strains were:

a. Medium of production: Figure 1 (a) indicated that variable amounts of EPS could be achieved using different media. Relatively low EPS yields were maintained using MRS, however, the maximum EPS yield was recorded in case of sucrose broth. Similar results were obtained by Khadem $\mathrm{H}$. et al, 2012. As the
Effect of essential oils on EPS production: In order to evaluate the effect of essential oils of two plants (A.H. and H.S.) on EPS production, strains were grown in a medium supplemented with essential oils at different concentrations: 50, 100 and $150 \mu$ respectively.

Kinetic of production of EPS: The kinetics of production were followed on broth sucrose under optimal conditions over a period of $72 \mathrm{~h}$. EPS production was estimated at several time intervals $(2 \mathrm{~h}, 4 \mathrm{~h}, 18 \mathrm{~h}, 24 \mathrm{~h}$, $48 \mathrm{~h}, 72 \mathrm{~h}$ ).

Isolation and quantification of exopolysaccharides : After incubation, the cultures were maintained in the water bath at $100^{\circ} \mathrm{C}$ for $10 \mathrm{~min}$. Then they are cooled for $10 \mathrm{~min}$ at room temperature $\left(25^{\circ} \mathrm{C}\right)$, treated with $85 \%$ trichloracetic acid solution (v/v) and centrifuged at 13,000 rpm for 20 minutes (Frengova et al., 2000). After removal of the cells and protein by centrifugation, the EPS was precipitated with ethanol (90\%). The EPS was recovered by centrifugation at $14,000 \mathrm{rpm}$ for 20 minutes. Total EPS (expressed as $\mathrm{mg} / \mathrm{l}$ ) was estimated in each sample by phenol-sulphuric method (Dubois et al., 1956) using glucose as standard (Torino et al., 2001).

In vivo test (measure of viscosity): To evaluate the effect of stem strains in vivo, skim milk was inoculated with the strains (S1, S2, S3 and S4) at $1 \%$ volume (Dupont, Roy, \& Lapointe, 2000).

Statistical analysis: All experiments were repeated in duplicate. All data were presented as means \pm SE. Frequency of isolated strains was examined for statistical significance using analysis of variance (ANOVA) (Fisher's test). A $p$ value of 0.05 was considered as the threshold to declare a statistically significant difference.

composition of the growth medium has an important influence on EPS production (Cerning et al., 1994).

b. Concentration of inoculums: As showed in figure 1 (b) the highest yield of EPS was collected with $10^{7} \mathrm{UFC} / \mathrm{ml}$. Results revealed a proportional relationship between initial inoculum concentration and EPS production under optimal value. Similar results were obtained by Amar Yacine et al., 2012.

c. Temperature: The optimal temperature for EPS synthesis was $30^{\circ} \mathrm{C}$ for the strains Lactobacillus rhamnosus and Pediococus damnosus (1), $37^{\circ} \mathrm{C}$ for Leuconostoc mesenteroïdes and $50^{\circ} \mathrm{C}$ for Pediococcus damnosus (2) as shown in Figure 1(c). Leo et al., 2007 indicated that Lactobacillus fermentum TDS030603 is able to produce more EPS at 37 than at $40^{\circ} \mathrm{C}$. On the other hand, the growth and exopolysaccharide (EPS) 
production by Lactobacillus fermentum $\mathrm{F} 6$ increased to a maximum value of $44.49 \mathrm{mg} / \mathrm{l}$ of EPS at $37^{\circ} \mathrm{C}$ (Zhang et al., 2011).

d. $\quad \mathrm{pH}: \mathrm{pH}$ is one of the most important factors, which can influence growth, and production of particular products by lactic acid bacteria. In this study, the final rate of EPS was higher at $\mathrm{pH} 6.2$ for all strains except the strain $P$. damnosus (S4) to $\mathrm{pH}$ 5. Therefore, $\mathrm{pH} 6.5$ and 5 for $P$. damnosus (S4) was chosen for the rest of the study (Fig 1d). Bakry M. Haroun et al., 2013 results revealed that the maximum level of EPS produced by Lactobacillus plantarum was reached at $\mathrm{pH} 6.2$.

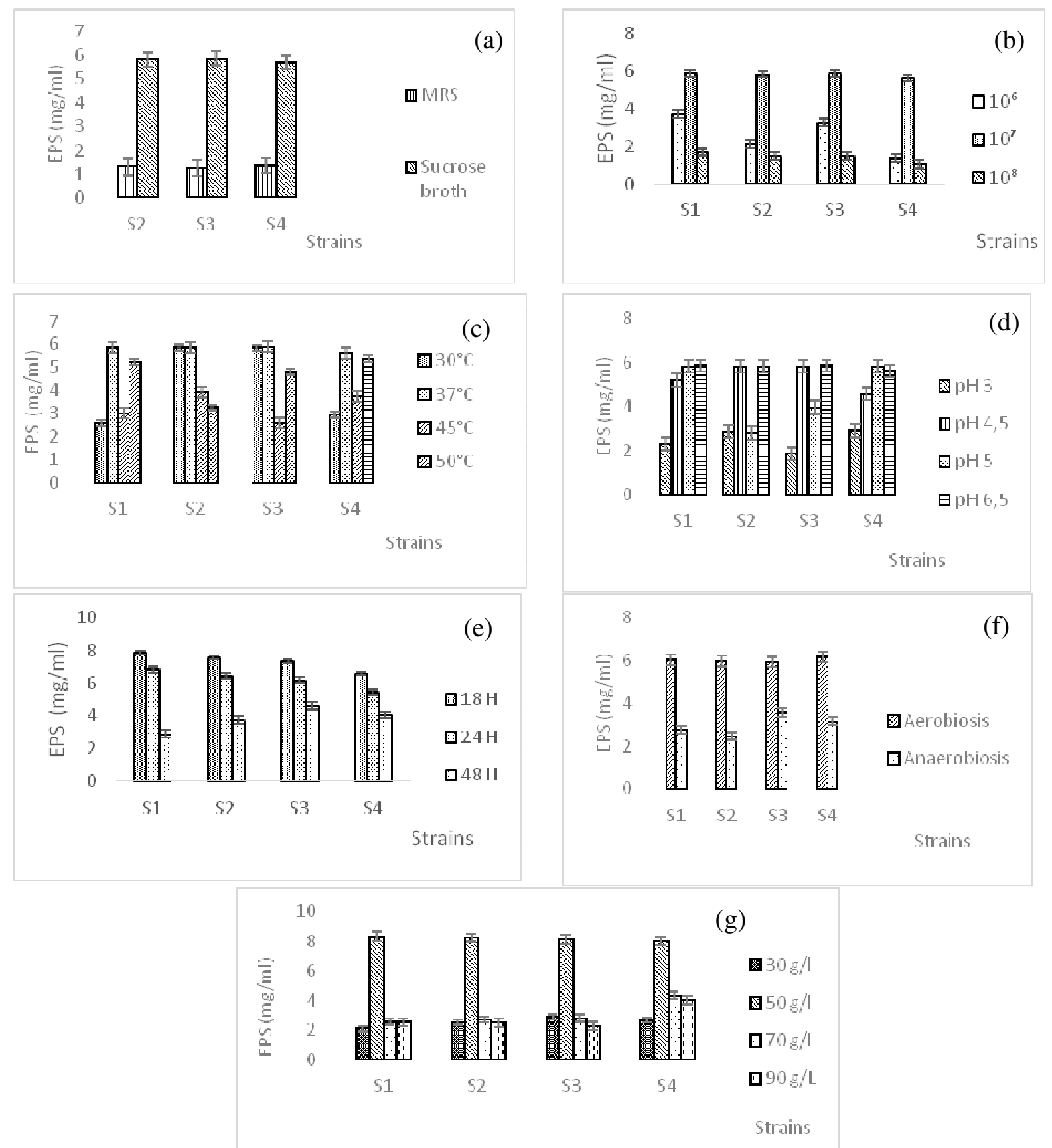

Figure 1: Effect of differents factors on EPS production: (a): medium of culture, (b): inoculum size, (c): temperature, (d): $\mathrm{pH},(\mathrm{e})$ : incubation period, $(\mathrm{f})$ : aeroanaerobiose, $(\mathrm{g})$ : concentration of substrate $[\mathrm{P}(0,05)]$ 
e. Incubation period: Results illustrated in figure $\mathrm{n} 1(\mathrm{e})$ indicate that biosynthesis of EPS was increased linearly to reach its maximal yield after $18 \mathrm{~h}$. Above this phase of growth; a decline in the EPS production was recorded, until a depletion of EPS production was observed at $48 \mathrm{~h}$. The most of EPS was produced during the 12 to $24 \mathrm{~h}$ incubation of the fermentation (Richard and Maria, 2003).

f. Conditions of Anaerobiosis: Results revealed that oxygen amount affects EPS production. Figure

g. $\quad 1 f$ showed that EPS production was maximal at aerobiosis for all strains. Studies of Amar Y. et al., 2012 and Khadem H. et al., 2012 reported that the highest level of EPS was obtained at aerobiosis.

h. Substrate: It has also been hypothesized that bacterial growth and EPS production are usually influenced by initial concentration of carbon (Wachenheim and Patterson, 1992). In this experiment, among the various concentrations tested, $50 \mathrm{~g} / \mathrm{L}$ was the most suitable for EPS production for all strains in concordance with research of Amar Y. et al., 2012 (Fig 1g). It has been noted that this parameter significantly affected the production of EPS.

\section{Effect of essential oils of two plants on EPS} production

Effect of E.O. from two plants on EPS production: The potential of essential oils for the production of EPS by the lactic strains was determined in this experiment. This study results (Fig. 2) showed that essential oils from two plants (A.H. and H.S.) stimulate selectively the EPS production where there was an increase in EPS level with increase of oils concentration. The higher production was obtained with $150 \mu$ l for all strains.

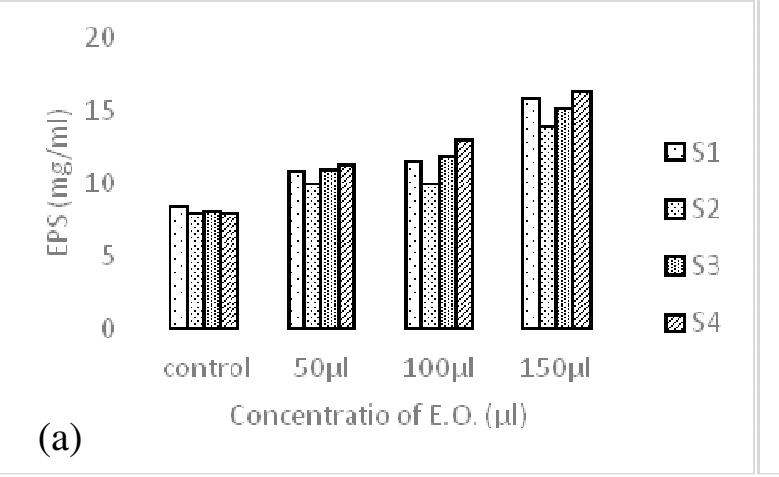

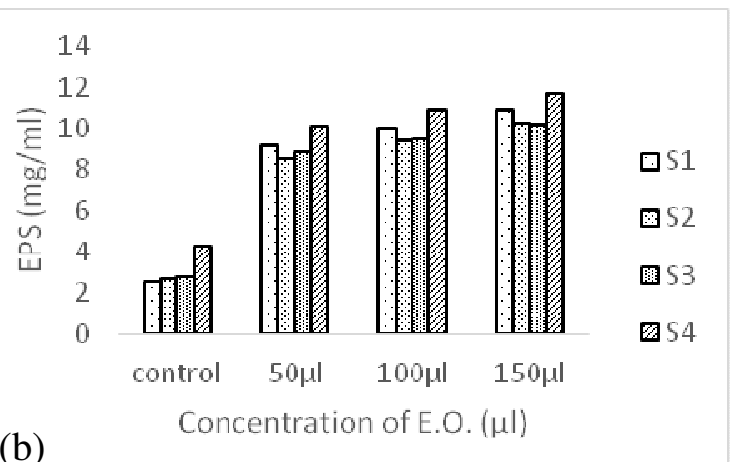

(b)

Figure 2: Effect of essential oils of medicinal plants on EPS production. (a): E.O. of Atriplex halimus, (b): E.O. of Haloxylon scoparium

Kinetic of EPS production: The results presented in Figure 3 indicated that the addition of essential oils of plants (A.H. and H.S.) improved the production of EPS by studied strains but the kinetics of production were same with and without essential oils. However, the highest production of EPS was observed with the strain Pediococcus 2 (S4). EPS was produced mainly during the exponential growth phase and continued slightly in the stationary phase. Similar observations were reported for other EPS-producing LAB strains (Duenas et al., 2003).
Many studies showed a decrease in the total EPS amount upon prolonged fermentation. The decrease is difficult to explain since viscosity measurements may be affected not only by the amount of polysaccharides released by the cells, but also by other metabolic products such as lactic acid and proteins (Walling et al., 2005). However, growth associated and non-growth-associated production of EPS by LAB has been observed before (Manca de Nadra et al., 1985; Kojic et al., 1992; Looijesteijn and Hugenholtz, 1999). 

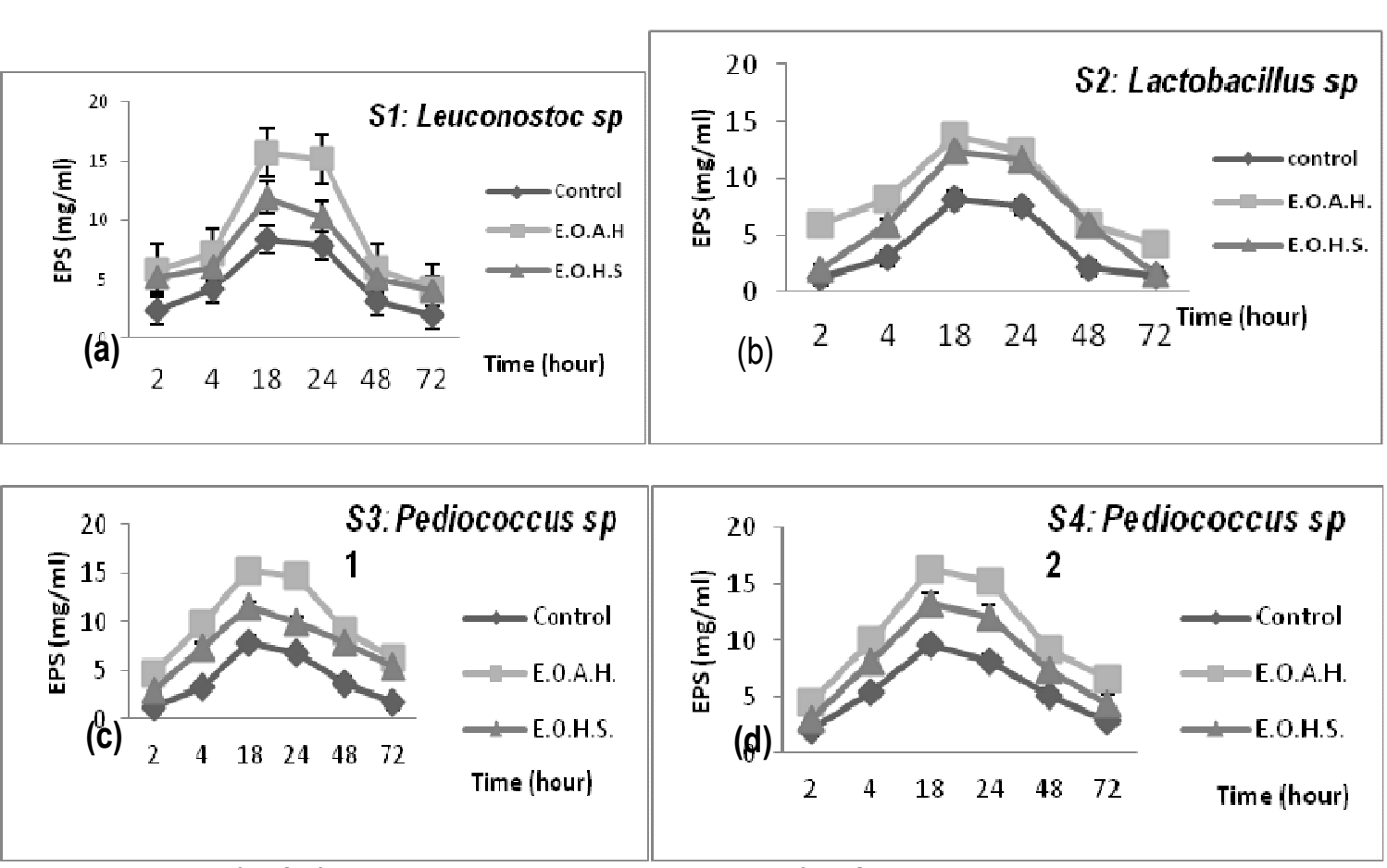

Figure 3: Impact of E.O. from two medicinal plants on kinetics of EPS production in each strain

In vivo test (Viscosity test): There was an obvious change in viscosity during the fermentation period, indicating that EPS production had occurred. On the other hand, the study found an increase in viscosity when essential oils were added to cultures of strains (Figure 4). Moreover Pediococcus damnosus 2 (S4) represent the excellent strain in terms of improving viscosity. Exopolysaccharides produced by some strains of lactic acid bacteria have been found to improve textural properties in fermented dairy products (Ruas-Madiedo et al., 2002).

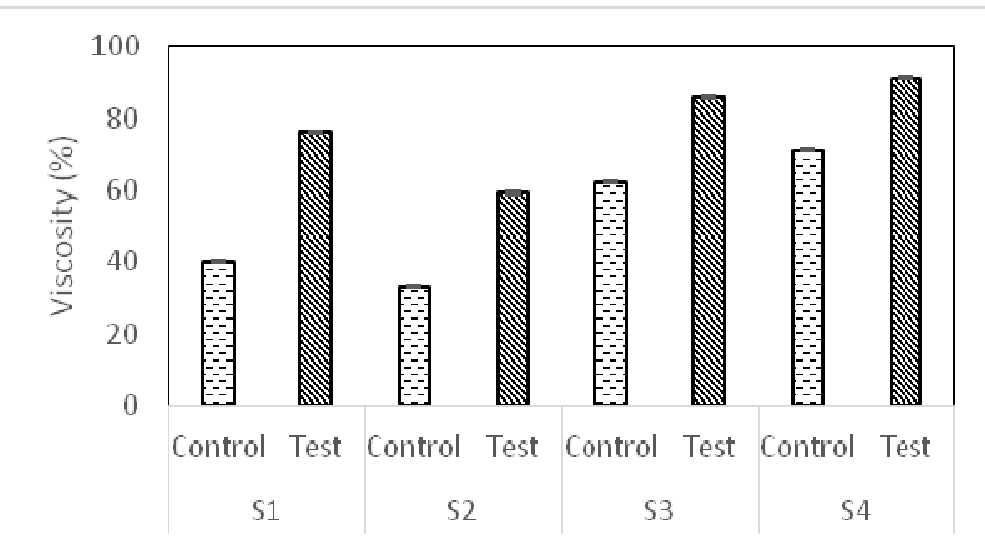

Figure 4: viscosity of skim milk inoculated with different strains

\section{CONCLUSION AND APPLICATION OF RESULTS}

This study showed that the strains have their ability to produce extracellular polymers. The essential oils of two plants Atriplex halimus and Haloxylon scoparium may exert a selective stimulation on EPS production. The results from this study revealed that some substances, such as essential oils, could be used as a substitute substrate for the EPS production. Although the obtained results do not allow direct extrapolation, they are an indication of the possible ability of essential oils to be used to optimize EPS production. In vivo studies are 
needed to confirm the optimizing effect of essential oils of medicinal plants from the production of

\section{ACKNOWLEDGEMENTS}

We are thankful to Prof. A. Meddah Tir Touil, Department of Microbiology, Bioconversion, Microbiological,

\section{REFERENCES}

Amar Sidi Med El -Yacine. 2008. Assessement of the prebiotic character of a dietary fiber and confirmation of a probiotic effect of two bacterial strains. Thesis of Doctorate, University of Mustapha Stambouli, Mascara, Algeria.

Bakry M. Haroun, Hassaan A. El- Menoufy, Hala A. Amin, Amr A. El-Waseif. 2013. Biosynthesis and Morphology of an Exopolysaccharide from a Probiotic Lactobacillus plantarum under different growth conditions. Journal of Applied Sciences Research, 9(2): 1256-1265, 2013 ISSN 1819$544 X$

Cerning, J., C.M.G.C. Renard, J.F. Thibault, C. Bouillanne, M. Landon, M. Desmazeaud and L. Topisirovic, 1994. Carbon source requirements for exopolysaccharide production by Lactobacillus casei CG11 and partial structure analysis of the polymer. Appl. Environ. Microbiol., 60: 3914 \pm 3919 .

Chikhi llyas.2013. Chemical composition and biological activities of extracts of five plants, aromatic and medicinal plants of wast of Algeria. Thesis of Doctorate in chemistry, option: bio-organic Chemistry \& Therapeutic. University Abou Bekr Belkaid, Tlemcen, Algeria.

Degeest, B., F. Mozzi and L. De Vuyst, 2002. Effect of medium composition and temperature and $\mathrm{pH}$ changes on exopolysaccharide yields and stability during Streptococcus thermophilus LY03 fermentations. International Journal of Food Microbiology, 79: 161-174.

De Man, J.C., M. Rogosa and E. Sharpe, 1960. A medium for the cultivation of Lactobacilli. J. Appl. Bacteriol., 23: 130-135.

De Vuyst, L. \& Degeest, B., 1999. Heteropolysaccharides from lactic acid bacteria. FEMS Microbiol Rev 23, 153-177.

Doleyres, Y., L. Schaub and C. Lacroix, 2005. Comparison of the functionality of exopolysaccharides produced in situ or added as bioingredients on yogurt properties. Journal of Dairy Science, 88: 4146-4156. exopolysaccharides.

Engineering and Health Security Laboratory for providing all facilities.

Dubois, M., Gilles K. A., Hamilton J. K., Rebers P. A., and f. S ITH. 1956. Calorimetric method for determination of sugars and related substances. Anal. Chem. 28: 350-356

Duenas, M., A. Munduate, A. Perea and A. Irastorza, 2003. Exopolysaccharide production by Pediococcus damnosus 2.6 in a semidefined medium under different growth conditions. International Journal of Food Microbiology, 87: 113-120.

Frengova, G. I.; Simova, E. D.; Beshkova, D. M. and Simov, Z. I. (2000), Production and monomer composition of exopolysaccharides by yogurt starter cultures. Canadian J. Microbiol., 46, 1123-1127.

Hao LM, Xing XH, Li Z, Zhang JC, Sun JX, Jia SR, Qiao CS, Wu T (2010). Optimization of effect factors for mycelial growth and exopolysaccharide production by Schizophyllum commune. Appl. Biochem. Biotechnol., 160: 621-631

Kaditzky S, Vogel RF (2008). Optimization of exopolysaccharide yields in sourdoughs fermented by lactobacilli. Eur. Food Res. Technol., 228: 291-299.

Khadem Hafida, 2012. Application d'une méthode alternative d'immobilisation des bactéries lactiques pour l'optimation de la production des E P S sous l'effet des flavonoides naturels.MS thèse University of Mustapha Stambouli Mascara

Kojic, M., Vujic, M., Banina, P., Cocconcelli, P., Cerning, J., Topisirovic, L., 1992. Analysis of exopolysaccharide production by Lactobacillus casei CG11, isolated from cheese. Appl. Environ. Microbiol. 58, 4086-4088.

Korakli, M., Ga"nzle, M. G., \& Vogel, R. F. (2002). Metabolism by bifidobacteria and lactic acid bacteria of polysaccharides from wheat and rye and exopolysaccharides produced by Lactobacillus sanfranciscensis. Journal of Applied Microbiology, 92, 958-965.

Kumar, Praduman, Mruthyunjaya and Dey, Madan M. (2007) Long-term changes in food basket and 
nutrition in India, Economic and Political Weekly, (September 1): 3567- 357

Leo, F., S. Hashida, D. Kumagai, K. Uchida, H. Motoshima, I. Arai, S. Askuma, K. Fukuda, and T. Urashima, 2007. Studies on a neutral exopolysaccharide of Lactobacillus fermentum TDS030603. J. Appl. Glycosci., 54: 223-229.

Looijesteijn, P.J., Hugenholtz, J., 1999. Uncoupling of growth and exopolysaccharide production by Lactococcus lactis subsp. cremoris NIZO B40 and optimization of its synthesis. J. Biosci. Bioeng. 88, 178-182.

Manca de Nadra, M.C., Strasser de Saad, A.M., Pesce de Ruiz Holgado, A.A., Oliver, G., 1985. Extracellular polysaccharide production by Lactobacillus bulgaricus CRL 420 . Milchwissenschaft 40, 409-411.

Natesan Sivakumar, Muthuraman Sundararaman and Gopal Selvakumar, 2012. Full Length Research Papern Probiotic effect of Lactobacillus acidophilus against vibriosis in juvenile shrimp (Penaeus monodon). African Journal of Biotechnology Vol. 11(91), pp. 15811-15818, 13 November, 2012 Available online at http://www.academicjournals.org/AJB DOl: 10.5897/AJB12.1328ISSN 1684-5315 @2012 Academic Journals

Otmani Fatiha, 2014.Study of antioxidant activity of essential oil of Haloxylon scoparium Pomel in the Naâma region. Master memory. University Abou Bekr Belkaid- Tlemcen.Algeria.

Richard, T. and C. U. Maria, 2003. Isolation and characterization of two exopolysaccharides produced by Lactobacillus plantarum EP56. Research in Microbiology, 154: 705-712.

Ruas-Madiedo, P., R. Tuinier, M. Kanning, P. Zoon, 2002. Role of exopolysaccharides produced by Lactococcus lactis subsp. cremoris on the viscosity of fermented milks. Int. Dairy J., 12: 689-695.

Shivakumar S. and S. V. Vijayendra, "Production of exopolysaccharides by Agrobacterium sp. CFR24 using coconut water - a byproduct of food industry", Lett. Appl. Microbiol., 2006, 42, 477482.

Sivakumar, T., S.S. é $\quad$ 4Narayani, T. Shankar, and P. Vijayabaskar, 2012. Optimization of cultural conditions for exopolysaccharides production by Frateuria aurentia. International Journal of Applied Biology and Pharmaceutical Technology, 3: 133-143.
Torino, M. I.; Taranto, M. P.; Sesma, F. and Font deValdez, G. (2001), Heterofermentative pattern and exopolysaccharide production by Lactobacillus helveticus 15807 in response to environmental pH. J. Appl. Microbiol., 91, 846852.

Van Calsteren M. R., Pau-Roblot, C., Begin, A. \& Roy, D. (2002). Structure determination of the exopolysaccharide produced by Lactobacillus rhamnosus strains RW-9595M and R. Biochem J 363, 7-17.

Van Geel-Schutten G.H., Flesch F., ten Brink B., Smith M.R., Dijkhuizen L., 1998, Screening and characterization of Lactobacillus strains producing large amounts of exopolysaccharides, Applied Microbiology and Biotechnology, 50 (6): 697-703

Van Hijum, S. A. F. T., Bonting, K., van der Maarel, M. J. E. C. \& Dijkhuizen, L. (2001). Purification of a novel fructosyltransferase from Lactobacillus reuteri strain 121 and characterization of the levan produced. FEMS Microbiol Lett 205, 323328.

Vaningelgem F., Zamfir M., Adriany T. and de Vuyst L., "Fermentation conditions affecting the bacterial growth and exopolysaccharide production by Streptococcus thermophilus ST 111 in milkbased medium", J. Appl. Microbiol., 2004, 97, 1257-1273.

Vijayabaskar P., Babinastarlin S., Shankar T., Sivakumar T. and Anandapandian K. T. K. (2011), Quantification and characterization of exopolysaccharides from Bacillus subtilis (MTCC 121), Adv. Biol. Res., 5, pp. 71-76.

Vijayendra S. V. N. and R. S. S. Babu, "Optimization of a new heteropolysaccharide production by a native isolate of Leuconostoc sp. CFR-2181", Lett. Appl. Microbiol., 2008, 46, 643-648.

Wachenheim, D.E., Patterson, J.A., 1992. Anaerobic production of extracellular polysaccharides by Butyrivibrio fibrisolvens nyx. Appl. Environ. Microbiol. 58, 385-391.

Walling, E., M. Dols-Lafargue and A. Lonvaud-Funel, 2005. Glucose fermentation kinetics and exopolysaccharide production by ropy Pediococcus damnosus IOEB8801. Food Microbiology, 22: 71-78.

Willem J.P. 2004. Essential oils: medicine of the future. Edition: Estem Paris0. PP: 318-320. 
Xiaohua, W.U. and Z. Lina, 2009. E versus Z geometry in B -d-arabino-hexopyranosidulose oximes. Carbohydrate Research, 344: 2209-2216.

Xu CP, Kim SW, Hwang HJ, Choi JW, Yun JW (2003). Optimization of submerged culture conditions for mycelial growth and exo-biopolymer production by Paecilomyces tenuipes C240. Process Biochem., 38: 1025-1030.

Xu R, Ma S, Wang Y, Liu L, Li P (2010). Screening, identification and statistic optimization of a novel exopolysaccharide producing Lactobacillus paracasei HCT. Afr. J. Microbiol. Res., 4: 783795.

Yuksekdag, Z.N. and B. Aslim, 2008. Influence of Different Carbon Sources on Exopolysaccharide Production by Lactobacillus delbrueckii Subsp. Bulgaricus (B3, G12) and Streptococcus thermophilus (W22). Brazilian Archives of Biology and Technology, 51(3): 581-585.

Zhang, Y., S. Li, C. Zhang, Y. Luo, H. Zhang, and Z. Yang, 2011. Growth and exopolysaccharide production by Lactobacillus fermentum F6 in skim milk. African Journal of Biotechnology, 10(11): 2080-2090. 